\title{
La literatura conversa, ambigüedades e interpretación
}

The writing of the conversos, ambiguities and interpretation

\begin{abstract}
Shai Cohen
Universidad de Navarra, Facultad de Filosofía y Letras, Departamento de Filología, Grupo de Investigación del Siglo de Oro (GRISO), Pamplona, España. Doctoranda PIF. Correo electrónico: scohen@alumni.unav.es
\end{abstract}

La literatura es, en gran parte, una expresión de empatía y de memoria. El siguiente artículo trata de una manifestación particular de emociones relacionadas con la identidad conversa después de la expulsión de los judíos durante el Siglo de Oro. La dura realidad de una identidad híbrida queda reflejada mediante una limitada voz, revelada, en la medida de lo posible, mediante la escritura. Es decir, obras como La Celestina de Rojas o La Lozana Andaluza de Delicado, entre otras, quizá formen parte de lo que se puede llamar literatura conversa. Sin embargo, tales sugerencias se han visto envueltas en una polémica interesante entre los partidarios que abogan por esta expresión literaria y los que las califican como análisis hiperbólicos. Por tanto, se da cabida a una discusión académica entre críticos literarios y se permite apreciar las diferentes perspectivas que se adoptan ante ella, además de preguntarse entonces: ¿cómo se percibe el converso en una obra literaria?

Palabras clave: literatura conversa, Lozana Andaluza, picaresca, La Celestina, judeoespañol.

The following article is about a manifestation of emotions related to the identity of the conversos after the expulsion of the Jews in particular and later during the Spanish Golden Age. Literature is in large part an expression of empathy and memory. Hence, the harsh reality of a hybrid identity is reflected by a limited voice revealed, to a certain extent, by their writing. That is, works such as La Celestina by Rojas, La Lozana Andaluza by Delicado and more are a part of what can be called converso literature. However, such suggestions have launched an interesting debate between some who advocate this literary expression and others that look at this analysis as hyperbolic and irrelevant. Therefore, it allows for an academic discussion of literary critics while reviewing the different perspectives that arise in it, posing the question: how the converso is perceived in this literary work?

Key words: converso literature, lozana andaluza, picaresque, la celestina, judeo-español. 
La libertad, Sancho, es uno de los más preciosos dones que a los hombres dieron los cielos; con ella no pueden igualarse los tesoros que encierra la tierra ni el mar encubre: por la libertad, así como por la honra, se puede y debe aventurar la vida.

(Quijote II, cap. LVIII 2005: 980).

La polémica alrededor de la existencia de una "literatura conversa"1 debe ser tratada a partir de la búsqueda de las causas, la motivación para crear y desarrollar tal género. Tal aseveración queda confirmada con los hechos históricos, ${ }^{2}$ tomando como punto de partida la existencia del fenómeno etno-social conflictivo. Cada cambio social está motivado por una dinámica de intereses y poderes de las partes en conflicto. En este caso, como muchos otros antes y después del Siglo de Oro, se trata de una coexistencia conflictiva de minorías de distinta filiación étnica y religiosa que llegó a provocar el miedo y/o rechazo de la mayoría cristiana. ${ }^{3}$ La reacción más habitual era recurrir al baluarte del poder social, económico y político del Estado por parte de dicha mayoría. El sentimiento de amenaza suele ser manipulado por las partes interesantes que modelan y estimulan las crisis. La aparente amenaza a la libertad suele impedir, además, cualquier acto de introspección, lo cual aumenta el sentimiento de miedo en la sociedad. Como en todo caso de crisis, la población recurre a acciones de represión y castigo dirigidos al responsable (a menudo virtual pero no sin consorcio alguno) para reconquistar el sentido de control, que, de su parte, restaura un sentido de libertad.

Desde luego, ello genera una cadena de acontecimientos manipulativos. Al principio, se identifica una serie de sucesos en un momento específico y en un lugar específico. ${ }^{4}$ Luego, contrariamente a lo esperado, estalla la crisis que provoca una represión repentina pero premeditada. La represión se manifiesta entre otras formas, en el acallamiento del grupo en cuestión. Este enmudecimiento da lugar a una introspección que quiere ser contada y comunicada, sin poder hacerlo. En este momento surge un tipo de literatura; cuanto mayor nivel educativo tenga el grupo en cuestión, más desarrollada será su obra. La literatura aporta, también de su parte, un sentido de libertad y control, por virtual que sea, sobre el enfrentamiento con la realidad.

Presento a continuación un breve resumen de lo señalado para esquematizar la teoría:

Literatura conversa o literatura de conversos, según Ruth Fine, que analiza a la vez la literatura escrita por conversos y la que trata y habla de conversos (Fine 2010: 309-319).

2 Para un estudio de los antecedentes históricos y/o para una base de información histórica que resumiera las circunstancias extratextuales de las que emerge la noción de literatura de conversos, se puede ver entre otros: Amrán (2008), Baer (1959), Caro Baroja (2000), Castro (1967), Fine (2010), Gilman (1978), Sicroff (1985).

3 Es importante recordar que no había pasado tanto tiempo desde que habitantes cristianos de la península habían estado bajo la ocupación musulmana, siendo ellos mismos la minoría.

4 Según la noción de unicidad de Mijaíl Bajtín en Toward a Philosophy of the Act (1993). 

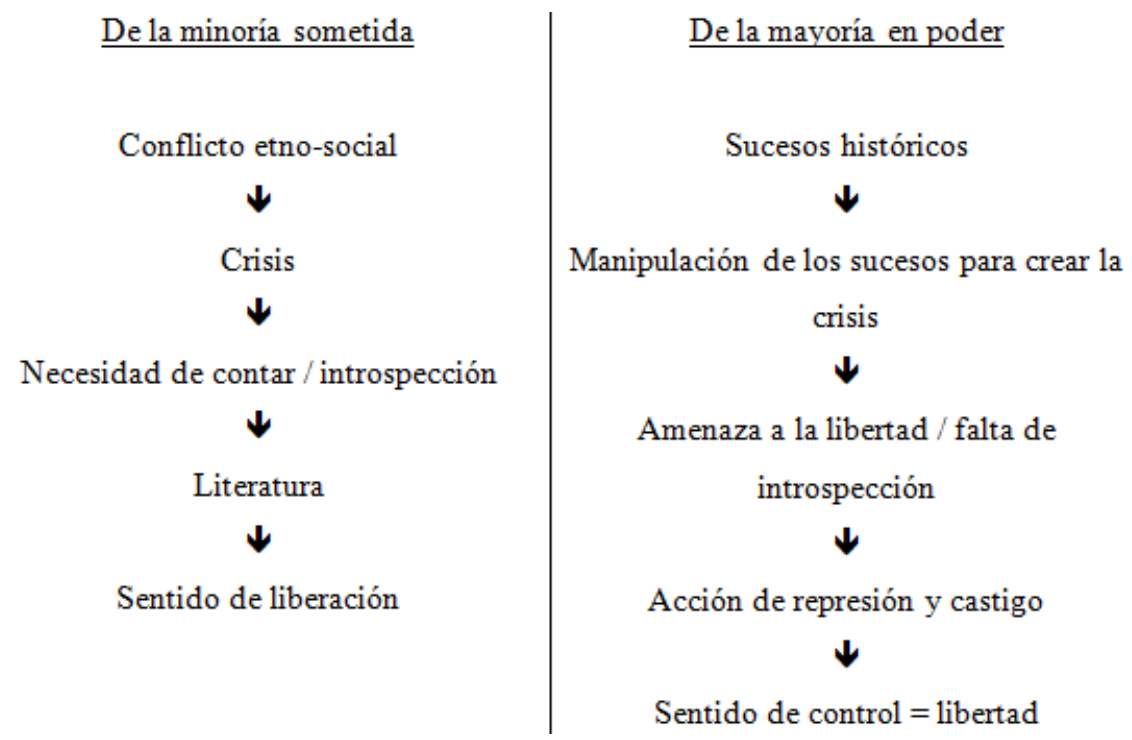

Evidentemente, cada cual de estas fases es una etapa que depende de homogeneidad y especificidad de los dos grupos y que se desarrolla en escalas cronológicas definidas. Así por ejemplo, emerge una etapa de crisis en el último cuarto del siglo $\mathrm{XIV}$, que provoca la conversión forzada (pero todavía no general). Luego, el siglo $\mathrm{XV}$ es el más decisivo, con trastornos importantes que modificaron intensamente las circunstancias. Cada etapa halla su representación particular en la literatura tanto ensayística como de entretenimiento y tanto judía conversa como cristiana.

Ahora bien, el surgimiento de una nueva clase etno-civil afectó el proceso literario pero no de modo homogéneo. Se trata de manifestaciones diversas y en muchos casos disímiles, tales como la melancolía, el trauma, la preocupación por la identidad, la visión invertida del otro, etc.

Respetando el orden cronológico desde una perspectiva del judío y, más tarde, del converso, se puede notar cómo luego de un ecumenismo de convivencia, el cinturón católico se abrocha y cuanto más fuerte se hace, más inseguro el ser social minoritario se siente. Así por ejemplo, todavía en 1470 se podía ver a teólogos importantes como Rabí Simuel hablando de teología cristiana en la sinagoga de la villa. En 1499, el arzobispo de Sevilla autorizó a los judíos a que pasearan procesionalmente la Torá por las calles de la ciudad detrás del Santísimo Sacramento (durante una grave peste que sacudió la ciudad). No obstante, cada vez las manifestaciones judías serán más escasas, hasta ser anuladas.

Para intentar explicar esta noción circular del desarrollo histórico-literario en la época, presento el siguiente esquema. Se trata de cuatro fases que se continúan: la primera es la percepción de la realidad (por el autor); luego, por lo traumática que es, surge el deseo de introspección y, seguidamente, de contar su realidad; después de eso está evocada la creación literaria; y por último, se trata del trabajo de lectura y decodificación de esa obra por parte de su receptor. De este modo se observa cómo el trabajo literario afecta la realidad mediante la provocación de un horizonte interpretativo que modela la percepción de la realidad. De hecho, se trata de un circuito permanente, que se desarrolla conceptual y cronológicamente. 


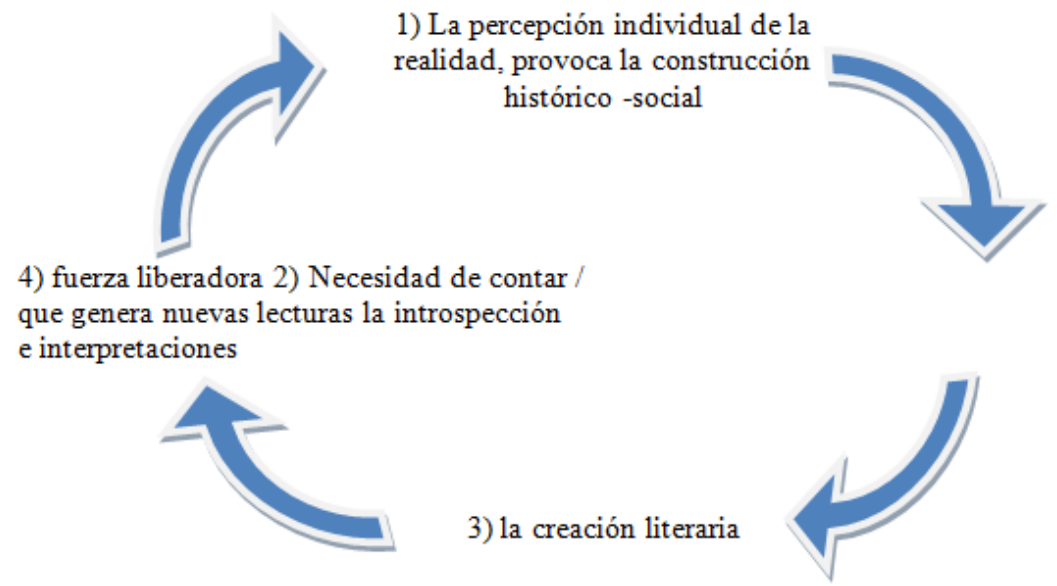

La existencia de un género converso, con un acicate ideológico-literario, reafirma una problemática que resulta bastante difícil de resolver. ¿Por qué los conversos eligieron la literatura como plataforma ideal para la transmisión de sus testimonios, para la comunicación y la expresión de la injusticia y la discriminación, de modo más o menos consciente? En su artículo sobre la representación conversa en Cervantes y Rojas, Fine constata:

Las conversiones masivas, las conversiones acomodaticias, la conversión como opción ante la posibilidad de expulsión y la expulsión misma constituyen un fenómeno reconocible de trauma colectivo [...]. Se trata de un proceso singular de transformación colectiva, durante el cual el grupo se ve enfrentado a una serie compleja de dilemas en todos los órdenes. [...] la experiencia traumática, entonces, ha sido la fundente. Ella entraña una repetición de la huella mnémica, a través de procesos simbólicos diversos, que pueden detectarse textualmente a partir de blancos, residuos, eufemismos, intermitencias (Fine 2009: 251).

En su investigación, Fine muestra la expresión del dolor paternal en el caso de la reacción de Pleberio tras el suicidio de su hija, Melibea, en La Celestina de Roja, y la voz quijotesca que aparece en la decepción de Agi Morato tras la conversión de su hija Zoraida. En los dos casos, los protagonistas emergen de los márgenes y mediante sus voces se manifiesta de nuevo el conflicto acallado de la conversión.

Por su parte, Hartman intenta responder a la pregunta: ¿por qué contar mediante la literatura y no solamente, o principalmente, mediante tratados de hechos reales, de acontecimientos históricos bien grabados en la memoria y hasta en la carne de las personas? En su artículo sobre el estudio del trauma, afirma:

Tanto en los estudios literarios como en el campo de la salud pública surge una nueva conciencia que es ambas ética y clínica. Hay más escucha, de palabras dentro de palabras, y una mayor apertura al testimonio. [...] Al igual que en la literatura, encontramos una manera de recepción de la historia, de escucharla, de dibujarla en una conversación interpretativa. Se evita el reduccionismo médico o político. Los expertos no tienen la 
última palabra. La historia, Kathryn Hunter dice, “debe ser devuelta al paciente” (Hartman 1995: 548; traducción propia). ${ }^{5}$

Hartman señala que se trata del uso imaginativo del lenguaje en lugar de una transparencia del significado. En parte, es la ruptura de la tradición trasmitida a lo largo de generaciones que evoca esta sensación traumática. La comunidad judía del siglo $\mathrm{XV}$, aunque relativamente separada de la sociedad mayoritaria, probablemente deseaba volver a ser una comunidad homogénea y el deseo o sueño es la marca del trauma. La comunidad judía siempre vivió como una comunidad cerrada al mundo externo (salvo por razones de comercio y política). Eso creó un sistema de comportamiento social y comunitario que contribuyó al mantenimiento de la comunidad como tal, así como de su tradición religiosa y social. Por lo tanto, la transgresión o la violación de esta tradición significaba, para muchos, el sufrimiento. Por otro lado, se plantea también la cuestión del trauma físico. En tal sentido, Nietzsche afirma en la Genealogía de la Moral que el castigo físico, auto-infligido o no, "ayuda", desde un punto de vista peyorativo, a la memoria a grabarse con más profundidad y causa cicatrices tanto en la psique como en el cuerpo.

$\mathrm{Al}$ parecer, las obras escritas por conversos crean un proceso de recuperación de la identidad mediante la anagnórisis que el texto es capaz de elaborar. Delicado, por ejemplo, ofrece muchos indicios a lo largo de su texto, como el llamar a los capítulos “mamotretos”, término que se relaciona con la memoria, la cual, como he dicho, desempeña un papel central en la literatura de los conversos. Claude Allaigre dice que uno de los significados posibles de la palabra 'mamotreto' sería “traído a la memoria", ${ }^{6}$ lo que remite a la perspectiva moralizadora: "con este significado 'memorándum' (traído a la memoria) se abre una perspectiva moralizadora; pero no ha llegado aún el momento de justipreciar la seriedad de las intenciones didácticas del autor” (Allaigre, en Delicado 2003: 31).

\section{EL CONVERSO: PERSONA, PERSONAJE Y PROTAGONISTA}

fueron y eran judíos secretos, y no eran ni judíos ni christianos pues eran baptizados, mas eran hereges.

(Crónica de los Reyes Católicos)

Como lo aclara Amrán (2008), la "identidad conversa" fue definida por el cristiano viejo, quien creó la noción de los conversos, marranos, meshumadim, anusim, cristianos nuevos, judeoconversos, tornadizos, alboraycos y judaizantes, ${ }^{7}$ en toda su variación y heterogeneidad. Faur (1990) define cuatro clases de conversos: 1. Los

«Both in literary studies and in the field of public health a new awareness arises which is ethical as well as clinical. There is more listening, more hearing of words within words, and a greater openness to testimony. [...] As in literature, we find a way of receiving the story, of listening to it, of drawing it into an interpretive conversation. Medical or political reductionism is avoided. The experts are not given the last word. The story, Kathryn Hunter says, "must be returned to the patient” (Hartman 1995: 548).

6 Sobre este tema véase el excelente estudio de José Manuel Martín Morán, "Memoria e identidad en La Lozana Andaluza" (2003). El autor trata allí, entre otros múltiples aspectos, la importancia que da Delicado a la memoria.

$7 \quad$ Para una explicación detallada sobre las diferencias, se puede ver Amrán (2008) y Fine (2009). 
conversos que querían ser cristianos, negar y separarse por completo del judaísmo y su representación. Este fenómeno existió desde el nacimiento del cristianismo, a lo largo de toda la historia y hasta la actualidad. 2. Los que querían ser judíos sin ningún nexo con el cristianismo. 3. Los que querían pertenecer a las dos corrientes religiosas. Por supuesto, muchos de ellos por motivos económicos, políticos y sociales, o simplemente por miedo. 4. Los que no querían seguir ninguna, ni el judaísmo ni el cristianismo. Ellos se corresponderían con los llamados averroístas, mencionados con relativa extensión en el estudio de Baer (1959).

A partir de esta división, se puede comprobar la dificultad existente ante la conversión con sus múltiples expresiones textuales y perspectivas. ${ }^{8}$ Una de las razones de la difícil tarea del estudioso del tema es la heterogeneidad y confusión en un escenario de identidades superpuestas y cambiantes, ya que esta división no considera al grupo de personas que cambian de una categoría a otra según la necesidad y la posibilidad. De este modo, el converso adquiere fácilmente los rasgos de un ser híbrido, sin identidad fija, una persona que se busca a sí misma dentro de una sociedad pronunciadamente estratificada y estigmatizadora.

En relación a esta búsqueda de identidad, hay críticos que sostienen que la literatura de los conversos también les servía como un tipo de red de comunicación interna. ${ }^{9}$ Otros mencionan el hecho de la necesidad de expresarse, manteniendo un tipo de diálogo interno para así intentar encontrar una respuesta. Sin embargo, en mi opinión, probablemente se trate de una amalgama de estas dos motivaciones y quizá muchas otras más.

Entonces, ¿por qué los judíos, primero, y los conversos, después, constituyen un objeto obsesivamente atendido? Muchos de los investigadores afirman que se debía a su poder económico y a su influencia política y social. Sin embargo, parecería que otra razón, más básica, que rige la mentalidad que engendra todas estas hipótesis, es también la que juega un rol determinante. Durante siglos los judíos consiguieron sobrevivir en el exilio, desterrados, en comunidades cerradas dentro de pueblos extranjeros. Su supervivencia se ha fundado en el mantenimiento de la religión judía como el más importante mandato y ello en un contexto comunitario. En otras palabras, se trata de la extensión del yo: todo lo que haría por mí ahora, lo hago por mi familia, es mi yo extenso, y después el de la familia, de mi vecindad, y después de la vecindad mi comunidad. Para los judíos en la diáspora, el yo extenso se limitó a la comunidad.

Diferentemente, en el cristianismo, lo divino es lo importante: hace falta dejar todo enlace con la tierra para llegar a la beatitud, para llegar al altruismo puro, hacia la unión con el Dios de la Gracia, la bondad, la pureza. Toda atadura a lo terreno no debe existir ya que estamos todos en nuestra forma física temporalmente y esa es una forma de preparación para el más allá. Como es sabido, la representación artística durante los siglos de oro españoles, prioriza el memento mori, el ars moriendi y otras conceptualizaciones relacionadas con la muerte y la vida del más allá.

Esta perspectiva dogmática tiende a ignorar y despreciar al otro, torturarlo en las cárceles de la Inquisición, ser partícipes de atroces autos de fe. El condenado no es más

Todorov $(1970,1982)$ estudia las diferencias de puntos de vista en los momentos culminantes de interacciones interculturales. En su estudio muestra una falta de conocimiento que lleva a conflictos basadas de interpretación errónea e imposición. Otro artículo interesante es de Zbinden (2006).

9 Un ejemplo importante es el que ofrece Gilman (1978) hablando de una comunicación tácita entre los conversos. 
que una marca de desviación en la creencia en la verdadera vida, que es la que espera después de la muerte. La consideración respecto del otro era totalmente anacrónica para la época y para el contexto regido por el dogma del catolicismo tridentino. ${ }^{10}$

\section{PERSPECTIVAS CRÍTICAS ANTAGÓNICAS}

A pesar de todo lo dicho, es importante recalcar que no todos los investigadores están de acuerdo con la perspectiva desarrollada hasta entonces, ni tienen el mismo entusiasmo y acicate respecto del tema que la mayoría de los investigadores mencionados aquí. Existen otras miradas que niegan esta tipología en la literatura del Siglo de Oro español.

Una rivalidad bien conocida en este campo es la de Américo Castro vs. Sánchez Albornoz, dos sabios investigadores de la historia española, a los que separaba, entre otros temas, un profundo desacuerdo respecto de la influencia y aportación conversa al mundo ibérico. Américo Castro estimaba que el aporte más sustancial a la historia de España fue la interacción del espíritu de judíos, musulmanes y cristianos, mientras que Sánchez Albornoz (1956) defendió la tesis de que fueron los romanos y visigodos quienes establecieron la mentalidad, la idiosincrasia y la cultura de la península ibérica. Otro investigador que refutó las ideas castristas fue Eugenio Asensio, en su aporte titulado La peculiaridad literaria de los conversos (1976). Allí rebate y aminora el peso de la cultura judía dentro del mundo converso. Uno de sus principales argumentos es el hecho de que los ex-judíos se sintieron más atraídos por el mundo cristiano (i.e. humanismo, estoicismo, cristianismo etc.) que por la cultura judía de sus antepasados. Sin embargo, tras el debate apasionado y extremo de la cuestión realizado por estos y otros especialistas, seguirán estudios más eclécticos y rigurosos, como los de Juan Carlos Garrot y Juan Diego Vila, a los que me referiré a continuación.

Es importante precisar que ninguno de los dos, ni Garrot ni Vila, niegan por completo la existencia de autores conversos, pero insisten fuertemente en la inexistencia de tal fenómeno como género literario. Para Garrot, la denominación de una literatura de conversos forma parte del "frenesí castrista": ${ }^{11}$

Hubo muchos tipos de conversos "biológicos” y la asimilación, la ocultación, el cambio de ciudad, los matrimonios mixtos, aumentan la heterogeneidad y difuminan la identidad. Este último elemento a veces se considera de manera algo frívola, quiero decir que el hecho de tener algún antepasado ex illis no infunde una personalidad particular, sobre todo cuando tanto el sujeto como la sociedad ignoran este punto (Garrot 2010: 2).

De hecho, Garrot destaca muchos aspectos importantes en cuanto a la cuestión de la identidad conversa, partiendo de las argumentaciones de Surtz, Round, Gilman, Ynduráin, Poliakov (desde su punto de vista antropológico), Menéndez y Pelayo, Caro Baroja, y más. Siguiendo la copiosa bibliografía de críticos, investigadores, poetas, novelistas y dramaturgos, Garrot estima como inconsistentes a los que reivindican esta palpable y ecuménica existencia. Su reclamo defiende la inexistencia de esta categoría en ciertos casos o su irrelevancia en otros, cuando estudiamos los autores y las obras de la época.

\footnotetext{
Para un estudio más detallado sobre el tema y solución hipotética, se puede leer la obra de Robert Wright (2002).

11 Refiriéndose, por supuesto, a Américo Castro y su tesis sobre la especificidad de la originalidad conversa.
} 
El crítico francés consagra un estudio a Lope de Vega y a Cañizares y Mota con sus discursos antijudaicos para proponer su tesis, contraria a la tesis que defiende la existencia de una literatura conversa. Mediante citas escogidas de la obra El niño inocente de La Guardia, Garrot afirma que en el teatro áureo hay una mención muy escasa de judíos, aunque recalca el aspecto antijudío de la obra de Lope, enumerando atrocidades contra judíos presentes en la pieza.

Por su parte, en su artículo, Vila (en prensa) utiliza un campo léxico relativamente más contundente y acusador diciendo que ciertos trabajos críticos han asumido "un posicionamiento tácito, lógico y natural, en términos ideológicos, con las políticas vigentes hoy día en el estado de Israel puesto que [...] ese tema sólo debería interesarle a un judío o [...] a un sionista activo y militante” (1) Dos de los ejemplos que propone son la crítica respecto de La Lozana Andaluza y El Poema del Mío Cid. En el primero, Vila muestra cómo en las tres ediciones, desde la de Bruno Damiani (1969) hasta la más reciente de Jacques Joset y Folke Gernet (2007), los editores se refieren en breve y sucintamente a una posible pero no probable relación conversa (fundada en la incomprobable condición de descendiente de judíos del autor, como también el recetario culinario). Si bien Vila no pretende probar éste ni otro origen para el autor de La Lozana, sí arguye lo "lastrado” y la irrelevancia del tratamiento de este tema por los editores mencionados. Su posición es la de analizar y fundarse en la complejidad de la identidad conversa, como punto de partida:

La categoría de converso, bien es sabido, es un escándalo ontológico desde múltiples ángulos. En primer lugar porque en los siglos XV, XVI o XVII nadie en su sano juicio aceptaría ser individualizado como tal ni se preciaría de pertenecer a un grupo de “cristianos nuevos” pues el estatuto de converso funda su operatividad no en la alegría de la pertenencia sino en la práctica injuriosa de la infamia. Y, en segundo lugar, porque este vaciado de referentes concretos en el pasado resulta muy peculiarmente suplido cuando los críticos confrontan entre sí (Diego Vila 8).

En realidad, su argumentación denuncia la investigación interesada y teñida de posicionamientos ideológicos. Vila reconoce que, desde cierta perspectiva, afirmar que todas las obras tienen ciertos problemas de identidad sería verdad a escala universal, ya que la gran mayoría de la literatura novelesca, teatral, hasta la poesía, tiene un protagonista, una historia y normalmente una problematización del tema identitario. Por tanto, la designación de literatura que privilegia lo identitario, se podría aplicar a toda la literatura mundial. Vila contextualiza la historiografía española a fin de entender el cómo y el porqué de semejante reacción ya que, para un español o un europeo cultivado y, más aún, tras los acontecimientos de la primera mitad del siglo $\mathrm{XX}$, denominar un mundo entero, una época cultural en relación al mundo judeoespañol sería problemático en extremo, cualquiera sea la posición político-ideológica del crítico en cuestión, como fue el caso de Menéndez Pidal o de Leo Spitzer (1970).

Ahora bien, la creación de la nueva clase o grupo social en España fue un hecho innegable. Su problematicidad, más aguda en las décadas cercanas a los eventos mismos y más diluida en los decenios que siguieron, no terminó de erradicarse y, paradójicamente, sufrió incluso momentos de recrudecimiento. El fenómeno pareció tener un asombroso poder de resistencia. No obstante, debemos tener en cuenta que el problema converso no fue el único relativo a las cuestiones de identidad en la 
época. El surgimiento del protestantismo y el llamado erasmismo alimentó también el problema identitario al principio del XVI. Los paradigmas en muchos casos se superponen y resultan difíciles de separar. Como es sabido, desde el año 1500 las obras de Erasmo de Rotterdam (1466-1536) se publicaban y circulaban ${ }^{12}$ basadas en el humanismo y con una visión nueva sobre la religión y el catolicismo. La influencia que tuvo sobre Lutero es innegable y, por tanto, muchos le acusaron de implantar el mal germen que llevó a la separación de la Iglesia de Roma. Muchos críticos estiman que los autores anónimos que escribieron los Lazarillos eran heterodoxos, protestantes o erasmistas, más que conversos de origen judío (y aunque fueran ambas cosas, lo que se destaca en sus obras es su perspectiva humanista, más que un posible origen mosaico lejano):

La nueva obra es hija de pleno derecho de su época, el humanismo de la segunda mitad del XVI: las referencias al pasado clásico, con manifiesta erudición, el interés por los asuntos patrios, la denuncia de la corrupción de la corte y del ejército español, la crítica de la situación religiosa, etc., hacen pensar en la actitud del hombre renacentista que fue su autor frente a tantos desmanes y ante las consecuencias del poder absolutista (Introducción de Piñero al Lazarillo 1999: 27)

Es indudable que los textos de una época establecen un tipo de comunicación o diálogo intertextual, ya sea de modo tácito o explícito, consciente o inconsciente. Tal como lo establece Bajtín, todo texto contiene las invitaciones a la respuesta que sus interrogantes suscitan. En mi opinión, es difícil negar la existencia de un tipo de literatura escrita en tiempos de alboroto, confusión y disturbios que afectaba a grupos humanos específicos. Los textos resultantes comunican este horizonte, ya sea desde la perspectiva del sujeto, del objeto, o de ambos. Si bien es compleja la designación de género para este corpus tan heterogéneo, su vigencia como manifestación literaria de un período y situación existencial específica me parece incuestionable. ${ }^{13}$

J. M. G. Le Clézio dijo en su discurso de recepción del premio Nobel (Octubre 2008): «Ecrire, si ça sert à quelque chose, ce doit être à ça: à témoigner. A laisser ses souvenirs inscrits, à déposer doucement, sans en avoir l'air».

Una comunicación tácita entre un grupo de personas que sufren una determinada situación común es un hecho probable. Por su parte, Leo Spitzer llamó al fenómeno de lectura que se corresponde con lo anterior la "pseudo-objective motivation”, o sea, encontrar el sentido en donde falta sentido, lo cual sería la misión implícita del lector. Una insalvable diferencia cronológica existe entre el tiempo del autor del período áureo y el del lector contemporáneo. La reconstrucción del período histórico es un medio para salvar esta diferencia, pero no es suficiente.

Se puede intentar e identificar la relación de obras del final del s. XV y de la

12 Entre las cuales se destacan Adagios (1500), Manual del caballero cristiano (1503), Elogio de la locura (1511). Asimismo, la traducción del Nuevo Testamento al latín, seguido de la Paráfrasis de 1516. De libero arbitrio diatribe (Sobre la diatriba del libre albedrío) de 1524, fue la obra que desencadenó la contestación de Lutero con su De servo arbitrio de 1525.

13 Ciertas definiciones de género podrían fácilmente adaptarse a nuestra perspectiva. Como dice en el diccionario Espasa: "Género - m. Conjunto, grupo con características comunes: género humano. [...] || Cada uno de los grandes grupos en que se pueden dividir las manifestaciones literarias según su objetivo, el asunto que tratan y cómo lo hacen, etc.: género narrativo, descriptivo" (Espasa 2000). 
primera mitad del s. XVI con la picaresca y con la literatura de conversos, en obras como La Celestina y La Lozana Andaluza. El análisis permite aducir la posibilidad de que Rojas o Francisco Delicado fuera, en efecto, un converso. ${ }^{14}$ Ello emerge de la lectura cuidadosa de diferentes episodios, entre otros, aquellos que muestran una vasta experiencia culinaria conversa, diferentes costumbres, comportamientos, etc. No obstante, todas ellas pueden ser marcas de representación de la problemática conversa, como también lo es el tema del padre o, más bien, del linaje, en el seno de un mundo de incertidumbre sanguínea. La filiación conversa del autor, si bien es posible, deja paso a la representación de un universo marcado por lo converso. Así, en estas obras, como más adelante en el género picaresco se observan muchas alusiones a la sangre judía o al deseo de ser considerado con sangre pura ("Quizá la sangre os tira, La Lozana Andaluza, mamotreto XI: 206).

Según el análisis, protagonistas como Lozana y Lazarillo son pícaros literarios ${ }^{15}$ en los que se identifican los rasgos que corresponden perfectamente al género (i.e. orfandad, vagabundear, búsquedas, deseo de medrar y más).

¿Identidad o identificación? En el paradigma converso emerge una dicotomía subyacente entre la identidad elegida o deseada por el individuo y su identificación por la sociedad. ¿Es importante que un converso se vea como cristiano o sólo tenía validez lo que la sociedad identificaba en él? ¿Quién era el verdadero Martin Guerre (su proceso también tuvo lugar en la segunda mitad del XVI)? Indudablemente, la mayor parte de los conversos no se sentían judíos ni criptojudíos, pero las marcas de su identidad les eran impuestas socialmente. Este es el conflicto que la literatura de conversos patentiza a través de sus manifestaciones diversas, plenas en subtextos. El problema de la conversión y de los conversos es aún hoy una fuente de interrogantes sin solución, como también lo son su realidad histórica y social y los textos literarios que los representan y les dan voz.

\section{OBRAS CITADAS}

Amrán, Rica (Dir.). 2008. Autour de La Celestina. Paris: Indigo. 123-142.

Anónimo. 2003. La Vida de Lazarillo de Tormes. Edición y notas de Milagros Rodríguez Cáceres/ Barcelona: Octaedro.

. 1988. La Segunda Parte del Lazarillo de Tormes, y de sus Fortunas y Adversidades, Edición de Pedro M. Piñero. Madrid: Cátedra Letras Hispánicas.

Asensio, Eugenio.1976. La España imaginada de Américo Castro. Barcelona: El Albir.

Baer, Issac. 1959. La historia de los judíos en España, Traducida del hebreo por José Luis Lacave. Barcelona: Riopiedras.

Bakhtine, Mikhaïl. 1978. Esthétique et Théorie du Roman. Traduit du russe par Daria Olivier. Paris: Gallimard.

Caro Baroja, Julio. 1972. Inquisición, brujería y criptojudaísmo. Barcelona: Ediciones Ariel. 2000. Los Judíos en la España Moderna y Contemporánea. Vol. I. Madrid:Istmo.

Castro, Américo. 1967. "Perspectiva de la novela picaresca" y "El Lazarillo de Tormes". Hacia Cervantes. Madrid: Taurus. 118-166.

Cohen, Shai. 2009. "Picaresca y Conversión en La Lozana Andaluza”. Revista Iberoamérica Global, 2, III: 126-148.

14 Para un estudio más sobre La Lozana Andaluza, v. Cohen (2009).

15 Para un detallado estudio sobre la figura del pícaro, ver Molho (1972, 1985), Reed (1981), Rico (1973). 
Delicado, Francisco. 2003. La Lozana Andaluza. Edición de Claude Allaigre. Madrid: Cátedra Letras Hispánicas.

Faur, José. 1990. «Notes et Mélanges, Four Classes of Conversos: a Typological Study». Revue des Études Juives CXLIX: 113-124.

1992. In the Shadow of History. Jews and Conversos at the Dawn of Modernity. Albany: State University of New York.

Fine, Ruth. 2010. "Reflexiones en torno a la literatura de conversos: un caso de hibridismo aurisecular”. René Ceballos y Claudia Gronemann (eds.), Passagem: Hybridity, Transmédialité, Transculturalidad. Hildesheim- Zürich- New York: Georg Olms Verlag. 309-319. . 2009. "Voces y silencios: Los llantos de Pleberio y Agi Morato o la representación del converso en Rojas y Cervantes”. In Rica Amrán (ed.), Autour de La Celestina. París: Índigo. 247-264.

Garrot Zambrana, Juan Carlos (en prensa), "La inaudible queja de los oprimidos: variaciones del antijudaísmo en Lope de Vega y Cañizares y Mota". Ruth Fine, Michele Guillemont y Juan Diego Vila (eds.), La literatura de conversos después de 1492. Frankfurt Am Main: Vervuert.

Gilman, Stephen. 1978. La España de Fernando de Rojas. Madrid. Taurus.

Hartman, Geoffrey.1995. “On Traumatic Knowledge and Literary Studies”. New Literary History 26,3: 537-563.

Martín Morán, José Manuel. 2003. "Memoria e Identidad en La Lozana Andaluza”. Artifara, Rivista di lingue e letterature iberiche e latinoamericane 2. En línea; disponible en http:// www.artifara.com/rivista2/testi/lozana.asp (julio 2003).

Molho, Maurice. 1972. Introducción al pensamiento picaresco. Madrid: Ediciones Anaya S.A. 1985. "El pícaro de nuevo". MLM 100, II: 199-222.

Reed, Walter L.1981. An Exemplary History of the Novel, the Quijotic versus the Picaresque. Chicago: The University of Chicago Press.

Rico, Francisco.1973. La novela picaresca y el punto de vista. Barcelona: Seix Barral, Biblioteca Breve.

Sánchez Albornoz, Claudio. 1956. España, un enigma histórico. Buenos Aires: Sudamericana, Vol. 2.

Sicroff, Albert A. 1985. Los Estatutos de Limpieza de Sangre, controversias entre los siglos XV y XVII. Madrid: Taurus.

Spitzer, Leo. 1970. Linguistics and literary history, essays in stylistics. Princeton, New Jersey: Princeton University Press.

Todorov, Tzvetan. (1970). "Las categorías del relato literario”. Análisis estructural del relato. Buenos Aires: Tiempo Contemporáneo. 155-192.

1982. La conquête de l'Amérique. La question de l'autre. Paris: Éditions du Seuil.

Vila, Juan Diego (en prensa). "La literatura de los conversos españoles: ¿Debate crítico o Damnatio memoriae?”. Ruth Fine, Michele Guillemont y Juan Diego Vila (eds.), La literatura de conversos después de 1492. Frankfurt Am Main: Vervuert.

VV.AA. 2000. Diccionario Espasa de la Lengua Española. Madrid: Espasa.

Wright, Robert. 2002. Non-Zero: The Logic of Human Destiny, New York: Pantheon.

Zbinden, Karine. 2006. "El yo, el otro y el tercero: el legado de Bajtín en Todorov". Acta Poética 27, I: 325-339. 
